\title{
TRUNCAR DE AIRES: A FLOR ETERNA
}

\author{
DIANA DUARTE FERREIRA \\ Universidade Nova de Lisboa \\ Lisboa, Portugal
}

Resumo: Este texto visa analisar as ligações entre Esaú e Jacó e o Memorial de Aires, inseparáveis do vínculo entre Machado de Assis, o Editor e o Conselheiro Aires. Para entender esses vínculos é fundamental distinguir noções como livro, romance e narrativa. O livro é o objecto que contém o texto. O romance é a ficção que apresenta a narrativa. Em ambos os romances é possível associar um nome diferente a cada uma dessas noções. Machado é autor do livro. Mas o Editor é quem inaugura, na Advertência, a ficção de ambos os romances. Constitui o protagonista, Conselheiro Aires, como autor suposto e póstumo das narrativas. Mas apresenta-as, em simultâneo, reformuladas e truncadas de acordo com um critério próprio.

Palavras-chave: Machado de Assis; Conselheiro Aires; Editor; Truncar; Simetria.

\section{AYRES' TRUNCATING: THE ETERNAL FLOWER}

\begin{abstract}
This text aims to analyze the connections between Esau and Jacob and Counselor Ayres' Memorial, which are inseparable from those between Machado de Assis, the Editor and Counselor Ayres. In order to understand these ties, it is fundamental to distinguish notions like book, novel and narrative. The book is the object that contains the text. The novel is the fiction that presents the narrative. In both of the novels it is possible to associate a different name to each of these notions. Machado is the book's author. But it is the Editor who inaugurates the fiction in the Foreword of each of these novels. He establishes the protagonist, Counselor Ayres, as the purported and posthumous author of these narratives. At the same time, however, he introduces them in a reformulated and truncated way at his own discretion.
\end{abstract}

Keywords: Machado de Assis; Counselor Ayres; Editor; Truncating; Symmetry. 
For the mystery is between them, and it cannot be invoked otherwise than in the figure they create together.

T. Adorno, "Late Style in Beethoven"

Quem me leu Esaú e Jacó talvez me reconheça estas palavras do prefácio [...].

M. de A.

Machado de Assis, Memorial de Aires

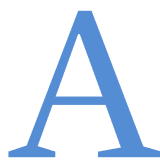

reprodução ficcional da autoria torna-se, desde logo, um problema central em Esaú e Jacó e Memorial de Aires. O Editor optou por assinar a Advertência do Memorial, ao contrário do que havia feito em Esaú e Jacó. Tal gesto de assinatura tem efeitos retroactivos; o Editor assume-se autor de ambos os romances. Nas iniciais "M. de A." encaixa o nome do autor, é certo. Mas, por outro lado, encaixa também o nome do livro. A Advertência de Esaú e Jacó termina com o título do livro. Poder-se-á dizer, perante essa simetria problemática, que o Editor assina o romance com o nome do livro? Ou que a publicação do livro é a derradeira assinatura? Machado de Assis é o único nome que permite a reunião de narrativa e romance numa "totalidade unificada" (BAPTISTA, 2003, p. 150) que não pode, todavia, deixar de remeter à cisão radical da figura do autor. Tal cisão reflecte-se na problematização da figura do livro.

Os romances têm a mesma progenitura, são como irmãos. Apesar dos quatro anos que distam a sua publicação em livro e, é claro, a sua escrita, consideramos que nascem juntos, bem à imagem dos gémeos Pedro e Paulo e Esaú e Jacó. Ambos se diferenciam na Advertência de Esaú e Jacó, na qual o Editor inaugura a dupla ficção que cinde o romance: por um lado "conta a história dos dois gémeos e de Flora [...] mas ainda, antes dessa e ao mesmo tempo que essa, acompanhando-a, a ficção que apresenta o Conselheiro Aires como romancista" (BAPTISTA, 2003, p. 143).

Embora a forma do Memorial em 1904 ainda não corresponda ao livro Memorial de Aires de 1908, é na Advertência de 1904 que nasce o projecto do romance, dentro e fora de parêntesis: "aparado das páginas mortas ou escuras, apenas daria (e talvez dê) para matar o tempo da barca de Petrópolis" (ASSIS, 2008, Advertência). Ora, são estas as "palavras do 
prefácio" que o Editor recita na Advertência de 1908, apresentando o Memorial reformulado de acordo com o critério anunciado em 1904: a conservação do mesmo assunto. Acrescentamos que as opções romanescas do Editor invertem a ordem de primogenitura das narrativas, que ele próprio deduz, e na qual o Memorial nasce primeiro.

A leitura de Esaú e Jacó evidencia que o "Memorial, diário de lembranças que o conselheiro escrevia desde muitos anos" (ASSIS, 2008, Advertência), é um dos pontos de convergência entre as duas ficções, a da narrativa e a do romance, para além de Aires enquanto personagem de uma e autor do outro. O narrador cita passagens do diário e não é possível, jogando o xadrez da ficção, saber se são reconstruções ficcionais ou transcrições autênticas. ${ }^{1}$ Mas é significante que a primeira citação do Memorial contenha a epígrafe de Esaú e Jacó, o verso truncado a Dante: Dico, che quando l'anima mal nata...

O Editor integra a trama da ficção autoral de forma controversa, criando na Advertência um encadeamento de níveis metaficcionais. Confessa, ao apresentar o romance de 1904, a incapacidade de justificar a razão de ser da "designação especial" de um dos sete cadernos manuscritos encontrados na secretária do Conselheiro após a morte, intitulado Último. É essa ausência de justificação ou razão de ser que, segundo o Editor, legitima a renomeação do livro. Mas contradiz-se ao admitir a disparidade evidente desse caderno em relação aos restantes, correspondentes ao Memorial e numerados de I a VI. Logo, podemos deduzir que o Editor compreende a necessidade de os títulos serem diferentes, por corresponderem, na génese, a formas radicalmente opostas; e que o que ele não compreende é a relação particular entre a narrativa legada por Aires e o título por ele designado. Mas justifica isso que o altere?

É inevitável que se questione esse gesto. Sobretudo porque uma Advertência sem usurpação do desígnio do autor, no que diz respeito ao título, seria ainda suficiente para constituir Aires como autor póstumo, quer da narrativa onde também é personagem, quer do diário a que chamou Memorial. Assim, "se a assinatura tem efeito de performativo jurídico, não apenas no sentido em que o ordenamento institucional da literatura dela

\footnotetext{
${ }^{1}$ Exemplo: No capítulo XXIII, o narrador evoca as barbas de "um amigo de Pedro, um capucho, um italiano, frei ***. Podia escrever-lhe o nome [...]" (ASSIS, 2008, p. 227). No capítulo LVII refere uma "valsa de Strauss ou uma polca de ${ }^{* * * "}$ (ASSIS, 2008, p. 282). Conta, no capítulo XXXII, que no Memorial havia pessoas "designadas por um X ou ***"; e Aires, na releitura habitual das suas recordações, "não acertava logo quem fossem, mas era um recreio procurá-las, achá-las e completá-las" (ASSIS, 2008, p. 241).
} 
depende, mas ainda porque o texto assinado legisla, estabelece uma lei, que impõe a si próprio e a quem o lê" (BAPTISTA, 2003, p. 148) e se "o Editor sublinha que Aires assinou de facto a sua narrativa no preciso momento em que inscreveu o título Último" (BAPTISTA, 2003, p. 145), o acto de usurpação do título não pode ser ilibado sem escrutínio prévio.

É certo que o título depende do autor e que o autor firma nele a sua assinatura. Mas o gesto de constituição do nome da obra tem o efeito paradoxal de a libertar. O título confere ao texto a condição básica da sua unidade essencial, poder ser referido. Ainda que Último possa remeter aos cadernos anteriores, é graças ao título que a narrativa tem a possibilidade de construir a figura de um destinador e "de se libertar da relação com os outros textos assinados por Aires, adquirindo, em suma, uma existência autónoma, que é, como se compreende, o que justifica a sua publicação separada do Memorial. Daí que apenas a narrativa se publique" (BAPTISTA, 2003, p. 144). Todavia, de acordo com este argumento em que nos apropriamos das palavras de Baptista, é inevitável discordar da conjectura que estabelece na frase seguinte: "e daí que o título seja alterado".

O Editor decide renomear a narrativa de Aires. Mas a justificação de recriar uma conjunção inteligível entre o título e a natureza do escrito, pressupondo que Último não o é, tem como base uma leitura subjectiva. O facto de Aires ter escolhido um título diferente para aquele caderno, "em conjunção com a natureza do escrito, sugere que a narrativa está disponível para uma situação de autonomia relativamente aos outros cadernos" (BAPTISTA, 2003, p. 145). E embora a morte de Aires abandone a narrativa à sua sorte, o próprio título Último, vicário do autor, não apenas sugere essa situação de autonomia: ao abrigo da ética, da jurisdição literária e da instância legitimadora constituída pelo acto de nomeação, chegaria mesmo a garanti-la.

A usurpação do direito à nomeação e a mudança de título constituem gestos radicais de truncagem. Como vimos, não era este um gesto imprescindível à inauguração das duas ficções do romance. Para tal bastava constituir Aires como autor suposto. Seria suficiente para que o problema da distância de Aires a Aires permanecesse insuperável. Mas só através de um gesto de truncagem como este é que o Editor podia gravar a sua assinatura, mais vincada do que teria sido, literalmente, a inscrição do nome no final da Advertência.

A suplementação da mudança de título demonstra que o efeito radical do autor suposto acaba por gerar não somente a ficção de autor, mas também 
o que chamaremos tripla ficção: a do autor real. O Editor implica o leitor na leitura de todas as ficções do livro quando o incita, com uma questão, a resolver o enigma apresentado como indecifrável: "Último por quê?" (ASSIS, 2008, Advertência). A tripla ficção alimenta-se do facto de só o nome Machado de Assis poder destinar o romance na sua totalidade. Mas vive, em simultâneo, dos limiares e cisões entre os planos de autor e de livro. Analisemos, no que diz respeito à narrativa, ao romance e ao livro, as simetrias entre os planos autorais da ficção e da realidade.

Em julho de 1903 Machado de Assis e o editor H. Garnier assinaram contrato para a edição de uma obra, de gênero não esclarecido, intitulada Último. O livro já devia estar escrito, ou em fase de conclusão, pois em novembro estava em provas. Em 15 de abril de 1904, era assinado um termo de contrato, mudando o título para Esaú e Jacó. (MACHADO, 2003, p. 259)

Os títulos debatidos na Advertência de 1904 correspondem a diferentes momentos da narrativa de vida machadiana. O confronto póstumo entre o Editor e Aires ilustra a contaminação do domínio da ficção pelo domínio da obra, logo reabsorvido pela literatura. A fronteira ficcional não é necessariamente fictícia. A luta desigual pelo título, entre um morto e um vivo, é representativa desta cisão. Machado destina, como Aires, ficções que satisfazem as condições necessárias para se separarem da origem e deixarem à sorte o nome do autor. A discussão do título, substancial, assinala a morte do autor suposto; mas remete, de igual modo, à morte e nascimento simbólicos do autor que assinou o primeiro contrato do livro e do autor que refez esse contrato, respectivamente. Ambas são certificadas pela assinatura, instância que legitima o novo termo de contrato. E o Aires e o Machado que julgavam ter escrito o último romance, ambos mortos, só podiam continuar a existir através da herança narrativa.

A atitude do Editor, descrita até aqui como questionável e infractora, em paralelo representa o gesto de um autor que sobrevive à própria sentença de morte. O póstumo não tem, todavia, como deixar de incluir o antigo: partilham a mesma memória. Não há romance sem narrativa. $\mathrm{O}$ mecanismo do autor suposto não anula uma assinatura em favor de outra. Assenta, sim, nas diferenças entre assinaturas de um único texto. Daí que o gesto de usurpação do título seja, ao mesmo tempo, o reconhecer do valor e da necessidade de preservação da memória e narrativa do antigo Machado e do falecido Aires, respectivamente. 
Estes processos de truncagem reflectem-se na distância entre Airesautor, truncado pela morte e pelas suas consequências, e Aires-personagem, truncado entre o lá fora e um espaço de interioridade que só é acessível pela escrita. Reforçam o carácter memorialístico de Esaú e Jacó, antevisto pela ligação indissociável a um memorial que é também o Memorial e confirmado pelo largo espectro temporal em que a narrativa decorre e abrange eventos históricos significativos. O capítulo "Esse Aires" termina com uma transcrição truncada do Memorial. A transcrição culmina no verso truncado de Dante que dá origem à epígrafe de Esaú e Jacó. O capítulo seguinte, "A epígrafe", retoma o verso retalhado do capítulo anterior: "Ora, aí está justamente a epígrafe do livro, se eu lhe quisesse pôr alguma, e não me ocorresse outra" (ASSIS, 2008, p. 213). Quem colocou de facto o verso de Dante no início do livro: Aires ou o Editor seguindo as instruções do narrador?

Referimos que o Editor clarifica, na Advertência de Esaú e Jacó, aquele que virá a ser o critério de truncagem do Memorial. Visando decotar um registo memorialístico das suas várias décadas, o Memorial de Aires publicado em 1908 nasce, assim, em 1904, enquanto projecto e com a intencionalidade de preservar somente o que ligar o mesmo assunto. Mas é a interrupção dos assuntos, intermediada pela escrita como assunto, que permite reconhecer no romance a forma de diário que por sua vez reforça o carácter romanesco do livro. Observemos como o critério de conservação do mesmo assunto também descreve a composição de Esaú e Jacó, não no plano do romance, mas no da narrativa. O estilo de narração acaba sendo mais romanesco ou novelizado do que a acção. O narrador, em constante diálogo com o leitor, aconselha-o a ler com atenção, porque as explicações "comem tempo e papel" (ASSIS, 2008, p. 200). Ora propõe adivinhas, porque o "leitor atento, verdadeiramente ruminante, tem quatro estômagos no cérebro, e por ele faz passar e repassar os atos e os fatos, até que deduz a verdade, que estava, ou parecia estar escondida" (ASSIS, 2008, p. 279), ora o censura pela pressa de tentar adivinhar (ASSIS, 2008, p. 234), ora chega a revelar a posição vulnerável da dependência de destinação, quando convida o leitor a penetrar o que no livro "for menos claro ou totalmente escuro" (ASSIS, 2008, p. 213), esperando que se trate de alguém com "visão bastante" para jogar o xadrez da ficção.

A cisão da narrativa é levada a cabo através de "um pensamento interior e único" (ASSIS, 2008, Advertência). Ou seja, através do estilo literário com que o narrador faz coexistir a narrativa do enredo e o enredo da narrativa. $O$ 
estilo vai intercalando sempre acção e parábase, diálogo e escrita: "Se não fosse a necessidade de pôr os meninos em pé, crescidos e homens, espraiava este capítulo. [...] Uma página bastava para os chocalhos [...]" - e segue atribuindo linhas e páginas até rematar numa paralipse: "Tudo isso restrinjo só para não enfadar a leitora curiosa de ver os meus meninos homens e acabados" (ASSIS, 2008, p. 218 e 219).

Continuidade e desfecho são forças motrizes de Esaú e Jacó: "se não fora o que aconteceu e se contará por essas páginas adiante, haveria matéria para não acabar mais o livro; [...] mas a história começada ficaria sem fim. Não, não, não... Força é continuá-la e acabá-la" (ASSIS, 2008, p. 327). É a ideia de desfecho que promove o nascimento e continuidade da narrativa dos gémeos. O narrador vai projectando no leitor a ansiedade de resolução das "cousas futuras", desde o primeiro capítulo. Quando faz depender deste episódio o começo do livro, tem já o "falar dobrado" (ASSIS, 2008, p. 195) de todos os oráculos. A pítia revela que os gémeos "serão gloriosos. [...] Quanto à qualidade da glória, cousas futuras" (ASSIS, 2008, p. 194). Mas Natividade e o leitor nunca saberão quais!

Os títulos dos capítulos muitas vezes antecipam o que só se pode ler no final dos mesmos. Essa é uma das formas de desviar o foco do plano da intriga para plano do mecanismo de exposição da intriga, sobrepondo este ao outro. Mas a função do desfecho é assegurada pela ideia de mesmidade. A engrenagem narrativa só pode referir-se ao desfecho da intriga, constantemente, cindindo a acção, através da conservação do mesmo assunto. A forma como está arquitectada, sem excepção, a transição de todos os capítulos, transforma a narrativa num manto de retalhos inconsúteis. Como? Conservando, claro está, o que liga o mesmo assunto. É assim que se ligam os capítulos: muitas vezes com associações e saltos temporais que só o anelo de pequenos motivos permite.

Todas as histórias, se as cortam em fatias, acabam com um capítulo último e outro penúltimo, mas nenhum autor os confessa tais; [...]. Eu adopto o método oposto; [...] A minha [...] é uma história simples, acontecida e por acontecer; o que poderás ver nos dois capítulos que faltam e são curtos. (ASSIS, 2008, p. 366)

A organização catafórica de Esaú e Jacó é evidente. Romance e narrativa vivem da antecipação do desfecho. A pergunta do Editor "Último por quê?" e o primeiro capítulo "Cousas futuras" concorrem harmoniosamente para esse efeito. Tanto que o último capítulo do livro se 
intitula, de facto, "Último". Afinal, o antigo título reflecte uma característica marcante da narrativa, a fixação pelo fim. O leitor poderá verificar que o enigma proposto pelo Editor não é totalmente irresolúvel. O reconhecimento deve levá-lo a reformular o enigma: por que Esaú e Jacó?

Porque o título Esaú e Jacó, ao contrário de Último, contempla a paridade e simetria que brotam de todas as dimensões deste livro. Dá conta das figuras geminianas que a publicação do livro faz nascer e assinala o nascimento do Memorial, a sua outra face. Representa o próprio truncar de Aires. Porque, como veremos, em Esaú e Jacó a ideia de mesmidade será ainda dominante: o desfecho do romance assenta na ideia de continuidade, porque a mesmidade do antagonismo é o que não tem desfecho.

O truncar de Aires-autor é mais conspícuo em Esaú e Jacó do que no Memorial de Aires. Sem a Advertência de 1904, Aires seria apenas personagem. Em 1908, a suposta autoria vem indicada no título e é corroborada pelo registo diarístico. Por outro lado, as características do diário contribuem para que o truncar de Aires-personagem seja mais palpável no romance de 1908. Só na dimensão da escrita é que Aires deixa extravasar, com sérias reservas e ludíbrios, o desejo por Fidélia. Se o tom confessional começa por acentuar a divisão entre o interior inconfessável e o exterior de Aires, a distinção entre fora e dentro vai esbatendo-se aos poucos e à medida que Aires vai deixando de destinar as páginas do diário ao fogo e começa a considerar dar a ler algumas a Fidélia e Tristão, ao casal Aguiar e à mana Rita. Passa a organizar a escrita, por vezes, de acordo com eventos catafóricos. Embora possam não acontecer, contaminam o Aires de dentro com a inconfessabilidade do exterior. O que não podia ser dito lá fora tornase indizível em absoluto.

A ideia de antagonismo tem forte representação no clássico confronto entre Deus e o Diabo, motivo frequente na escrita de Aires. Resumir-se-ia facilmente o debate se disséssemos que o Diabo tenta separar o que Deus faz por unir. Todavia, tal como na relação entre o nome Machado de Assis e o nome do autor suposto, a relação entre Deus e o Diabo implica um reconhecimento da autoria de um sobre o outro. Ou seja, implica um reconhecimento da autoria divina, sobretudo no que diz respeito ao próprio potencial de divisibilidade, separação e decomposição: mesmo porque este potencial deriva necessariamente de uma união, assim assegurada. O papel do Diabo é fomentar uma possibilidade criada pela mesma instância que o criou. O motivo da aposta é característico deste confronto. 
Descrita como "inspiração maligna", é uma reflexão ${ }^{2}$ do Conselheiro que dá o mote à aposta acerca da viuvez e casamento de Fidélia. O que Rita e Aires apostam, antes de mais, é a feição da alma de Fidélia, a lealdade e compromisso, tanto em vida como na morte, para com a alma do marido defunto. Esta aposta praticamente inaugura e alimenta o Memorial de Aires. Praticamente, porque a truncagem dos seis volumes leva a que este comece com uma efeméride, algo bem próprio de um diário. A efeméride é o regresso a casa graças à aposentadoria, uma espécie de desfecho continuado: "Aqui estou, aqui vivo, aqui morrerei" (ASSIS, 2003, p. 9). Embora o diário vede a possibilidade de catáfora, podemos observar indícios de como a ideia de desfecho também organiza a escrita deste romance, quer a partir das contingências do Aires que escreve, quer a partir da forma como o Editor transformou os seis volumes numa "narração seguida, que talvez interesse, apesar da forma de diário que tem" (ASSIS, 2003, Advertência).

A aposta reorganiza a escrita de Aires, porque o desorganiza. A instabilidade do Conselheiro oscila entre força motriz da escrita e da sua interrupção. O recurso ao verso truncado a Shelley, que ocorre diverso e em diversos momentos, é disso representativo. Shelley é primeiro mencionado sem o verso, depois de uma linha inteira de reticências (ASSIS, 2003, p. 15). Mas só adiante (ASSIS, 2003, p. 51) se complementa a explicação das reticências: "A mim mesmo perguntei se ela não estaria destinada a passar dos gelos às flores pela ação daquele bacharel Osório... Ponho aqui a reticência que deixei então no meu espírito". A segunda referência a Shelley (ASSIS, 2003, p. 19) é a primeira ao verso: I can give not what men call love... Aires acrescenta: "e é pena!", abrigando em simultâneo a frustração do desejo e a frustração dessa frustração, o próprio desejo. Chama-lhe "confissão". Não sente que seja "preciso dizer melhor para o fogo" a que ainda pretende destinar as folhas solitárias. Repete o verso que Shelley continuava a murmurar-lhe ao ouvido para que o repetisse a si mesmo, ainda inteiro. $\mathrm{O}$ verso surge truncado pela primeira vez quando Aires imagina casar com Fidélia: "ai, era preciso não haver esquecido o que aprendi, mas esqueci, tudo ou quase tudo. I can not etc." (ASSIS, 2003, p. 37).

Aires começa por se deixar levar "pela graça apetitosa da mocidade de Fidélia" (ASSIS, 2003, p. 20), mesmo sabendo que o desejo é incompatível com o seu lado de fora. A idade é o primeiro obstáculo. Aires defende os direitos da mocidade e acha que Fidélia deve voltar a casar. A viuvez de Fidélia, apesar de obstaculizante, é a premissa que lança a possibilidade de

2 "Não quer dizer que não venha a casar outra vez" (ASSIS, 2003, p. 12). 
um novo casamento. O obstáculo definitivo é o facto de a vontade de Aires ser sem acção. Quando Aires, a 8 de abril, se dirige ao papel pedindo que não recolha tudo o que escrever a sua pena vadia, já teme a destinação daquelas folhas. Quem o lesse pensaria que confiava ao papel "cuidados de amor" (ASSIS, 2003, p. 38). É o que o próprio Aires pensa, ou não pediria ao papel, qual Aires de fora dirigindo-se ao de dentro, que fugisse quando o sentisse insistindo nessa nota.

Rita diz que os olhos de Aires terão "dieta absoluta" (ASSIS, 2003, p. 16) porque não verão Fidélia. Aires emprega, por vezes, um léxico alimentício para se referir à viúva. ${ }^{3} \mathrm{O}$ lado tentador, expresso pelo paladar, é temperado pela feição de espírito, que Aires afirma ser o que mais lhe atrai em Fidélia. Com o passar do tempo, as graças da viúva cada vez parecem maiores, não só as do espírito: "se não a arrebatei comigo não foi por falta de braços nem de impulsos" (ASSIS, 2003, p. 53). Debate-se com a impressão intensa que Fidélia lhe provoca. A 24 de maio, sonha que Fidélia quer casar com ele. Reage com um distanciamento radical, procurando um desfecho último, "um desconcerto acabando em desconsolo". E acrescenta: "Aí deixo uma página feita de duas, ambas contrárias e filhas da mesma alma de sexagenário desenganado e guloso. Ao cabo, nem tão guloso nem tão desenganado. Conversações do papel e para o papel" (ASSIS, 2003, p. 49). É depois deste sonho que surge a referida explicação da reticência. Aires passa aí uma temporada sem escrever, regressando à escrita quando Osório sai de cena. Quando Tristão entra em cena, Aires põe-se "a rasgar cartas velhas" (ASSIS, 2003, p. 67). Rasgar cartas e deixar de escrever fazem parte do esquecimento, "ofício de defunto" (ASSIS, 2003, p. 99). Todavia, lendo notícias do regresso de Fidélia, a 2 de agosto confessa-se:

[...] cansado de ouvir que ela vem, mas ainda não me cansei de o escrever nestas páginas de vadiação. Chamo-lhes assim para divergir de mim mesmo. Já chamei a este Memorial um bom costume. Ao cabo, ambas as opiniões se podem defender, e, bem pensado, dão a mesma cousa. (ASSIS, 2003, p. 71)

No dia 21, descreve os "olhos cansados, acaso doentes", acrescentando: "não sei se continuarei este diário de factos, impressões e ideias. Talvez seja melhor parar. Velhice quer descanso." Mas no dia 24 reencontra o "certo

${ }^{3}$ Por exemplo: "não a achei menos saborosa que no cemitério [...]. Parece feita ao torno [...] falo das linhas vistas; as restantes adivinham-se e juram-se" (ASSIS, 2003, p. 18). 
gosto [de] deitar ao papel cousas que querem sair da cabeça. [...] Tudo é assim contraditório e vago também" (ASSIS, 2003, p. 81). A 17 de agosto:

Os olhos que pus na viúva Noronha foram de admiração pura, sem a mínima intenção de outra espécie, como nos primeiros dias deste ano. Verdade é que já então citava eu o verso de Shelley, mas uma cousa é citar versos, outra é crer neles. (ASSIS, 2003, p. 77)

A 18 de julho, após a partida do jovem casal, confessa: "Não acabarei esta página sem dizer que me passou agora pela frente a figura de Fidélia [...]. Sentou-se no canapé e ficámos a olhar um para o outro, ela desfeita em graça, eu desmentindo Shelley com todas as forças sexagenárias restantes" (ASSIS, 2003, p. 174-175). Fracturado pelo desejo, Aires diverge entre eros e thanatos, mas apenas na condição de não haver rostos desfigurados. Esse é um dos grandes motivos que o levam a concordar sempre. Talvez por isso recue pé ante pé perante a triste visão do casal Aguiar, órfão às avessas. Talvez por isso precise do verso de Shelley, a lembrá-lo que não pode dar o que os homens chamam amor se não pode nem ser visto sem a máscara, nem deixar de ver o outro com a sua.

Mas algo que não o desejo leva-o a sair, pontualmente, dessa esfera de comportamento. Pai postiço é o que tem uma "orfandade às avessas" (ASSIS, 2003, p. 176), o que nunca teve filhos. Aires enquadra-se nessa condição. Na sua alma "se descobriria acaso, entre as ruínas de meio celibato, uma flor descorada e tardia de paternidade, ou, mais propriamente, de saudade dela..." (ASSIS, 2008, p. 326). Natividade solicita a intervenção do Conselheiro junto dos gémeos, e este considerou que "não perdia muito em estudar os rapazes. Chegou a apanhar uma hipótese [...] vaga e colorida, a saber, que se os gémeos tivessem nascido dele talvez não divergissem tanto nem nada, graças ao equilíbrio do seu espírito" (ASSIS, 2008, p. 254). A hipótese é realmente vaga! Talvez "buscasse somente matéria nova para as páginas nuas de seu Memorial" (ASSIS, 2008, p. 258) - isto no ano de 1888, o mesmo em que Aires regista no Memorial, a 6 de fevereiro, que enquanto "o casal Aguiar morre por filhos, eu nunca pensei neles, nem lhes sinto a falta, apesar de só" (ASSIS, 2003, p. 31). Mas no dia 9 de setembro reconsidera: "Parece que a gente Aguiar me vai pegando o gosto de filhos, ou a saudade deles, que é expressão mais engraçada" (ASSIS, 2003, p. 91) - expressão que, como vimos, o Aires autor de Esaú e Jacó, ou melhor, de Último, havia usado. A 30 de setembro queixa-se: "nenhum dos meus filhos saiu do berço do Nada. 
Estou só, totalmente só" (ASSIS, 2003, p. 103). Aproveitamos para fazer um parêntesis, sublinhando outras coisas que Aires escreveu nesse dia:

Se eu estivesse a escrever uma novela, riscaria as páginas do dia 12 e do dia 22 deste mês. Uma novela não permitiria aquela paridade de sucessos. Em ambos esses dias - que então chamaria capítulos [...]. Riscaria os dous capítulos, ou os faria mui diversos um de outro [...]. Já lá vão muitas páginas falei das simetrias que há na vida [...]. Tudo isso repugna às composições imaginadas, que pedem variedade e até contradição nos termos. A vida, entretanto, é assim mesmo, uma repetição de atos e meneios [...]. (ASSIS, 2003, p. 102)

Aires escreve no diário o que faria de diferente se não escrevesse um diário, mas uma novela. E o Editor, que fez a novela a partir do diário, não só não seguiu as indicações de Aires, como as deixou ficar porque reforçam o lado romanesco do diário. Mas Aires, na narrativa Último, fez precisamente o que disse no Memorial que não faria caso escrevesse uma novela: uma repetição de simetrias em actos e meneios que, ainda assim, incluem bastante variedade e contradição nos termos. A passagem parece responder directamente a uma crítica de 1904, saída n'A Notícia (MACHADO, 2003, p. 259-260), e assim resumida: o temperamento dos gémeos levava-os "à fatalidade dos constantes desacordos. [...] O entrecho - todos os terão notado - peca por um excesso de simetria. [...] No caso, não há verosimilhança nem jamais foi verdadeiro".

Voltemos ao pai postiço. A verdadeira afinidade parental de Aires diz respeito não aos gémeos, mas a Flora:

[...] Aires ia sentindo como esta pequena lhe acordava umas vozes mortas, falhadas ou não nascidas, vozes de pai. Os gémeos não lhe deram um dia a mesma sensação, senão porque eram filhos de Natividade. Aqui não era a mãe, era a mesma Flora, o seu gesto, a sua fala, e porventura a sua fatalidade. (ASSIS, 2008, p. 274)

A fatalidade relaciona-se com a inexplicabilidade de Flora e, por conseguinte, com a do próprio Aires, "o oposto dessa contradição benigna" (ASSIS, 2008, p. 325). Em vez de concordar com tudo, Flora tentava conciliar diferenças. Aires chama a atenção da jovem, e esta comenta que o tem achado em contradição, de tanto o ver concordar. A "vida e o mundo não são outra cousa" (ASSIS, 2008, p. 325). Flora tem características idênticas às que 
parecem originar a afeição nova que Aires revela sentir por Fidélia no Memorial, como veremos: a capacidade de conciliar os opostos.

Flora acaba por morrer sem (ou por não) conseguir escolher um dos gémeos para casar. "Anda, Flora, ajuda-me, citando alguma cousa [...]. Cita Goethe, amiga minha, cita um verso do Fausto, adequado: Ai, duas almas no meu seio moram!" (ASSIS, 2008, p. 316-317). A citação surge após as visões de Flora, em que os gémeos se fundiam num só. A jovem acaba o capítulo pensando no Diabo. Vinha o Diabo unir o que devia existir separadamente? O narrador deixa bem claro que só a vaidade pôde convencer Natividade de que a maternidade seria uma boa aposta. Antes de os ter sentido "lutando dentro em si mesma" (ASSIS, 2008, p. 317), já tinha lutado dentro de si própria contra a ideia de ser mãe: "vinha agora uma criança deformá-la por meses, obrigá-la a recolher-se, pedir-lhe as noites, adoecer dos dentes e o resto? Tal foi a primeira sensação da mãe, e o primeiro ímpeto foi esmagar o gérmen" (ASSIS, 2008, p. 201). É a vaidade que a reconcilia com a maternidade e é a necessidade de se guiar por um desfecho que dê fundamento a essa vaidade que conduz a futura baronesa à cabocla do Castelo. Terá sido o Diabo, fomentado pela vaidade, a separar os gémeos, dando-se o caso de a inexplicável Flora ter o dom de um olhar reconstitutivo? "Era um espectáculo misterioso, vago, obscuro, em que as figuras visíveis se faziam impalpáveis, o dobrado ficava único, o único, desdobrado, uma fusão, uma confusão, uma difusão" (ASSIS, 2008, p. 315). A descrição também se aplica ao mistério que une os dois últimos romances machadianos, romances em que as ideias de contradição, paradoxo e antagonismo são constitutivas.

Aires escreve o que ia confessando à mana Rita: "o sentimento paterno que Fidélia acaso acorda em mim, [...] há cousas que apenas se devem escrever e calar, é o que eu faço a esta espécie de afeição nova que acho na viúva" (ASSIS, 2003, p. 155). É quando Fidélia se revela capaz de unir o inconciliável, superando a rivalidade entre o amor pelo defunto marido e o amor por um marido vivo, que Aires começa a sentir a afeição parental: "Tudo poderia existir na mesma pessoa, sem hipocrisia da viúva nem infidelidade da próxima esposa. Era o acordo ou o contraste do indivíduo e da espécie" (ASSIS, 2003, p. 130). "Creio nas afeições de Fidélia; chego a crer que as duas formam uma só, continuada" (ASSIS, 2003, p. 160).

Falta ver como os filhos postiços fazem o que não pode o desejo, levando Aires a abandonar as habituais normas de conduta. No que toca os gémeos, instiga-os a que decidam entre eles o que fazer em relação a Flora. 
No caso de Flora, rasga-lhe o desenho de "duas cabeças juntas e iguais. [...] Aires rasgava calado o desenho e metia os pedaços no bolso" (ASSIS, 2008, p. 343-344). Também o Aires do Memorial se vê no papel inusitado de representante do jovem casal, tendo de mentir ao velho casal Aguiar e ser porta-voz da notícia que leva ao desfecho deles e, quem sabe, de si mesmo. Os velhos, perante a revelação: "olhavam para lá, para longe, para onde se perde a vida presente, e tudo se esvai depressa" (ASSIS, 2003, p. 176).

Na botoeira, uma flor eterna. (ASSIS, 2008, p. 211, 239 e 370)

Cerca de 1870, aos "quarenta anos, ou quarenta e dois" (ASSIS, 2008, p. 211), já o Conselheiro exibia a flor eterna na lapela. Aos "sessenta anos" o "gesto grave" (ASSIS, 2008, p. 239), tal como a flor, continuavam. É também a flor eterna que remata Esaú e Jacó. O ornamento remete o leitor à elegância do Conselheiro, à harmonia do trato e à juventude do espírito. Mas não só. Pode referir-se, de igual modo, à retórica e à poética da personagem que é constituída como autor que se constitui como personagem.

Tudo indica tratar-se de uma imagem bela, coesa. Mas haverá beleza sem oposição? O que há de estável na flor eterna é justamente a oposição entre os conceitos representados pelas palavras que a constituem como expressão. É graças ao atributo imposto à flor, a eternidade, que o oxímoro adquire uma instância curiosa. No confronto entre a fragilidade da flor, substância, e a transcendência da eternidade, essência, a grandeza do atributo impõe-se perante a transitoriedade do objecto designado pelo nome, substantivando-se e reconvertendo o nome em atributo. O que pode uma "flor" perante o "eterno"? Os limites da definição do eterno coincidem com a ilimitação da sua abrangência e residem precisamente no facto de o eterno não poder ser integrado num nome e de não poder deixar de integrar todos os nomes.

No oxímoro de uma flor intemporal, a eterna juventude. Uma flor que nunca deu fruto, mas que também nunca murchou. Reflecte, de todo o modo, algo que no conselheiro sempre se mantém estável: o direito inabalável da mocidade e a necessidade, improvável numa personagem como esta, do antagonismo e da contradição. Mas, mais do que isso, é na mesmidade do antagonismo que a própria eternidade se revela e encobre, como se também fosse versada na arte da diplomacia.

Esaú e Jacó é um título proléptico. Simbólico, eco da antiguidade, remete até mais ao desfecho do romance do que Último. O Memorial remete ao desfecho de uma vida. Ambos vivem da ideia de desfecho, mas só vêm a 
encontrá-lo na unidade continuada que formam e na obrigatoriedade de se transformarem em algo que, por outro lado, continua exigir a manutenção do que tiveram de deixar de ser. Desconfiamos que nasceram assim.

\section{Referências}

ADORNO, Theodor W. Late Style in Beethoven. In: Essays on Music. Berkeley; Los Angeles; London: University of California Press, 2002.

ASSIS, Machado de. Memorial de Aires. Lisboa: Edições Cotovia, 2003. . Dom Casmurro \& Esaú e Jacó. Lisboa; Porto: Relógio d’Água, 2008.

BAPTISTA, Abel Barros. A formação do nome: duas interrogações sobre Machado de Assis. Campinas: Editora da Unicamp, 2003.

MACHADO, Ubiratan (Org.). Machado de Assis: roteiro da consagração. Rio de Janeiro: EdUERJ, 2003.

DIANA DUARTE FERREIRA é aluna finalista da licenciatura em Estudos Portugueses na Faculdade de Ciências Sociais e Humanas da Universidade Nova de Lisboa. Destaca literatura brasileira, teoria da literatura e estudos interartes como áreas de interesse e pesquisa académica. Instrumentista e criadora do Projecto Poeta, explora as convergências entre música e poesia, autoria e apropriação. (D) https://orcid.org/00000002-7554-2715. E-mail: diana.duart@icloud.com

Recebido: 08.09.2019

Aprovado: 16.10.2019 